\title{
Fostering Commonfare. Strategies and Tactics in a Collaborative Project
}

\author{
Peter Lyle \\ Madeira Interactive \\ Technologies Institute \\ Funchal, Portugal \\ peter.lyle@m-iti.org
}

\author{
Mariacristina Sciannamblo \\ Madeira Interactive \\ Technologies Institute \\ Funchal, Portugal \\ cristina.sciannamblo@m-iti.org
}

\author{
Maurizio Teli \\ Madeira Interactive \\ Technologies Institute \\ Funchal, Portugal \\ maurizio.teli@m-iti.org
}

\begin{abstract}
This paper contributes to the discourse on $\mathrm{HCI}$ and political economy, further developing theoretical concepts of strategies and tactics by drawing on the original work of French scholar Michel de Certeau. Strategies and tactics are developed and used as a lens to reflect and understand decisions made throughout an IT design process oriented toward infrastructuring social collaboration among people who are struggling financially. We demonstrate this by presenting the case of Commonfare, an EU funded project, and we focus, in particular, on the relationships between specific research and pilot project consortium partners. We explore decisions and actions that take place over four months between two milestones of the project - the first platform release, and a general assembly.
\end{abstract}

\section{CCS CONCEPTS}

- Human-centered computing $\rightarrow$ Collaborative and social computing; Participatory design;

\section{KEYWORDS}

Strategies and tactics, infrastructuring, participatory design

\section{ACM Reference Format:}

Peter Lyle, Mariacristina Sciannamblo, and Maurizio Teli. 2017. Fostering Commonfare. Strategies and Tactics in a Collaborative Project. In OzCHI '17: 29th Australian Conference on Human-Computer Interaction, November 28-December 1, 2017, Brisbane, QLD, Australia. ACM, New York, NY, USA, 5 pages. https://doi.org/10.1145/3152771. 3156154

Permission to make digital or hard copies of all or part of this work for personal or classroom use is granted without fee provided that copies are not made or distributed for profit or commercial advantage and that copies bear this notice and the full citation on the first page. Copyrights for components of this work owned by others than the author(s) must be honored. Abstracting with credit is permitted. To copy otherwise, or republish, to post on servers or to redistribute to lists, requires prior specific permission and/or a fee. Request permissions from permissions@acm.org. OzCHI '17, November 28-December 1, 2017, Brisbane, QLD, Australia (c) 2017 Copyright held by the owner/author(s). Publication rights licensed to Association for Computing Machinery.

ACM ISBN 978-1-4503-5379-3/17/11 ..\$15.00

https://doi.org/10.1145/3152771.3156154

\section{INTRODUCTION}

Recently, the HCI community has begun to question its own politics in different ways: in relation to the wider politicaleconomic context (e.g. [8]); by questioning how the people using technologies can be defined (e.g. [2]); and identifying progressive social subjects as allies for HCI researchers in advancing the discipline, such as the "makers" (e.g. [12]). Here we draw on our experience with a participatory design infrastructuring project - Commonfare - that aims to bring together different aspects of these discourses and the connection between politics and HCI. In this paper we elaborate on concepts of strategies and tactics in the context of infrastructuring, to show their potential to unveil power in a project embracing progressive politics and targeting economic inequalities (e.g. [6]).

The Commonfare project revolves around computing and social inequalities, and this paper builds on the theoretical concepts of strategies - plans/actions that relate to establishing space - and tactics - plans/actions that respond and react over time - as an approach to reflexively understand infrastructuring, as articulated by Bødker et al. [4] in HCI. These concepts are based on the work of the French scholar Michel de Certeau [5]. We apply these concepts as a means by which to describe and understand the relationships between different project partners (research and pilot) of an EU funded research consortium. We argue that these concepts provide a useful lens to understand relationships between different actors, different decisions made, and different perspectives on these decisions. This lens also offers an opportunity to pay closer attention to what Star and Bowker [15] refer to as 'issues of communication'. In discussing the way to build information infrastructures, Bowker and Star point to the ethical and philosophical problem of developing metadata standards in order to make a large-scale infrastructure work; In our case these issues of communication pose similar ethical concerns as they pertain to the problem of developing a language able to represent and engage participants in the project while holding another language standard accountable in front of fundings agencies [15].

The contribution of this work is, therefore, to articulate strategies and tactics as conceptual lenses beyond existing 
$\mathrm{HCI}$ literature to support reflexivity with regard to technology design in the context of infrastructuring (e.g. [4, 7]). Empirically, we narrow our focus to the connection between pilot and research partners of the Commonfare consortium, and to interaction over a four month period between two project milestones (a platform release, and a general assembly).

\section{INFRASTRUCTURING, STRATEGIES AND TACTICS}

Karasti and Baker [10, p. 1] articulate infrastructuring as "an ongoing design process that highlights participation and coconstruction, as well as the complex relationships between the long-term, data, participants, collaborations, information systems, and infrastructure". Pipek and Wulf [11] build on this, outlining a model to understand infrastructuring work as that which includes, and transitions from, design and development to appropriation and use. This transition occurs as part of a 'breakdown', where the infrastructure, once invisible (e.g. it exists in the background of daily life), becomes actively visible (e.g. when a new version of a software platform is released). This breakdown transition is referred to as a 'point of infrastructure' [11].

Both strategies and tactics are concepts that relate to understanding the decisions and actions and, in the context of infrastructuring, to the design and development, and appropriation and use. De Certeau [5, ch. 3] articulates strategies as "...the calculation (or manipulation) of power relationships that becomes possible as soon as a subject with will and power (a business, an army, a city, a scientific institution) can be isolated. It postulates a place that can be delimited as its own and serve as the base from which relations with an exteriority composed of targets or threats (customers or competitors, enemies, the country surrounding the city, objectives and objects of research, etc.) can be managed". This establishment of space sets the bounds and expectations within an infrastructuring project, and, in our case, the accepted and funded project proposal, with its milestones and reporting deadlines, serves as a grounding example.

By contrast, tactics represent a different kind of decision and action, which de Certeau [5, ch. 3] introduces as ".... calculated action determined by the absence of a proper locus. No delimitation of an exteriority, then, provides it with the condition necessary for autonomy. The space of a tactic is the space of the other". The focus of tactics is that, by being unable to define the space in which it operates, they are inherently mobile and reactive where strategies are not. This means that to operate tactically is to understand that there is likely an incomplete knowledge or model of the space, and that a mixture of wit and opportunistic pragmatism will allow for effective improvisation.
While strategies and tactics are defined in contrast to one another, they are not opposites or exclusionary, nor is one a subset of the other. They have a different goal: the goal of strategies is in the definition and "establishment of place", while the goal of tactics is on the "utilisation of time" [5, ch. 3]. The relationship between strategies and tactics is defined in terms of power in that strategies entail control carried out by leaders who follow a logic of competition, whereas tactics fall into the scope of non-powerful as an adaptation of the environment defined by strategies from the top, according to a logic of cooperation.

The exploration of strategies and tactics as presented by de Certeau [5], within the broad domain of technology design has been explored by other work by Dourish [7] and Bødker et al. [4]. Dourish [7] provides a discussion of strategies and tactics as they relate to concepts of space (and place). He suggests generalising spatial tactics beyond how individuals move through space to consider "flows of people, goods, capital, and information" as a way of thinking more broadly about the concept. Bødker et al. [4] by contrast engage in a discourse closer to our interest, providing a connection between infrastructuring and strategies and tactics, as a response to changing circumstances of a local self-organised community. They observe a series of strategies and tactics that take place over the course of different technological developments of the constellation of technical artifacts the community owns and uses, in particular, their website and payment system. Neither have used these concepts reflexively, as a way to look specifically at the organisation of infrastructuring practices involving design researchers as actors. Filling this gap is the goal of this paper.

\section{THE CASE OF COMMONFARE}

The Commonfare project aims to design a digital platform with the purpose to connect people and initiatives across Europe in order to confront societal issues such as poverty, low income, precariousness, and unemployment. The project articulates its actions in three European countries, focusing on different populations considered at risk of material deprivation or social exclusion [9], including: unemployed youth, precarious workers, non-Western migrants and freelancers. Against this backdrop, Commonfare aims to build a software platform - Commonfare.net - with the following goals: (1) to inform about public measures contrasting poverty, (2) to share good practices on how to cope with critical conditions, and (3) to find support in networking activities able to bring use value (or direct income) to people's everyday life.

The project presents a distinct interdisciplinary character involving academic actors with different training and research interests, non-academic actors such as local partners, and technical partners who develop the software platform. The partnership with non-academic actors responds 
to the need of overcoming language barriers (academic researchers mostly speak English), and to the belief that technology designers need to develop forms of cooperation with politically-engaged actors. This is in order to foster long term sustainability of the built technologies, grounded in the practices and values of cooperation as already demonstrated by different forms of platform cooperativism $[1,13]$.

Here we focus on the relationship between the institution where the authors of this paper are situated, and three pilot partners (hereafter referred to as Pilot 1,2,3) which act as the connection between the consortium and the local populations of pilot site countries. This particular relationship serves to highlight an example of the connection between academics and those who participate in research activities, mediated by the pilot partners. The empirical data supporting our discussions and example is drawn from multiple sources from within the project: 1) Contributions to a Shared Dialog: All consortium partners contributed to a dialog, responding to questions about: their organisation and its agenda, their experience with bottom-up/interdisciplinary research. 2) General Assembly Meeting Minutes: These meeting minutes include updates of the pilot partners project experience. 3) Periodic Meeting Minutes: This includes two meetings with each of the pilot partners to discuss and build a shared understanding of how a 'field activities plan' could be tailored to their expertise and environment. Finally, 4) Report: A milestone report [3] assembled by the pilot partners that presents empirical research focusing on understanding the priorities of people experiencing poverty and social exclusion.

From these empirical materials, we have extracted a brief description of the pilot partners as follows: Pilot 1 "is an international, ongoing social art project initiated in 2011". In Commonfare, they engage with freelancers, and non-western migrants. Pilot 2 is an organisation "at the nexus of public policy research and advocacy for the promotion of peace, antidiscrimination and socio-economic equity". For the project, they focus on unemployed youth. Finally, Pilot 3 "is a bottomup association born in 2008 to promote initiatives, debate and pressure in favour of the introduction of a basic income in [our country]". They work with precarious workers as target population to be involved in Commonfare.

The relationship between us and the pilot partners has been similar to the one described by Teli et al. $[16,17]$ in a different case: 1 ) both the design researchers and the partners are highly skilled with some research experience; 2) the partners have both the access and the competences to work with people "in the field"; 3) design decisions are taken in a constant dialogue in which both empirical activities and design directions are mediated by recurrent meetings, documents, and a peer-to-peer exchange among design and pilot partners. In practice, that means for the design researchers to be "people with design skills" in a wider context and not top-down drivers and narrators of others' activities. Our focus on strategies and tactics in this paper is indeed a way to reflexively think about the complex relationship that has been just described.

\section{CONDUCTING DESIGN RESEARCH AS A CONSORTIUM}

This example draws from a period of four months, from March to June of 2017. In the context of the project, it is situated immediately after the first platform release and ends at a general assembly of the whole consortium. It represents the perspective of the authors, as we, together with colleagues at University of Trento, sought to conduct research activities to 1) elicit feedback on the first release of a web platform (a simple information page) and 2) looking forward to the second release, where interactive storytelling features were to be designed and developed. This was motivated by the time-line funded by the EU, and its need was supported by the feedback received from partners during the general assembly. Early in March, after the platform was first released, we created a 'field activities plan' for activities to happen during April and May. Mid March we shared this plan with the consortium, which detailed our goals as above, and provided seven example design activities that could be used as a starting point for adapting for the different pilot partner contexts. Between late March and mid April we had two meetings with each pilot partner that focused on tailoring the plan. The pilot partners then conducted workshops and focus groups based on this tailoring process, and we received reports on these workshops between late April and early June. These reports then became the basis for discussion at the next general assembly, which occurred mid June. The different pilot partner's backgrounds, as well as their existing connections with relevant communities, distinctly shaped their approach to tailoring the field activities plan for their local context:

Pilot 1's background includes expertise and knowledge of storytelling and of visual design, this was reflected in the way they discussed how to approach their contacts, and the type of activities they would focus on in order to address the stated goals. This included a focus on different aspects of what would make for a good storytelling experience, the role of the author and audience, and the perspective from where a story could originate. They expressed the intention to run three different workshops (in different cities). From their existing connections to relevant local communities they intended to engage with an experienced storyteller who could give help advise them on running an effective workshop about storytelling.

Pilot 2 understood there was a need for storytelling to support whistle-blowing, to highlight corruption and injustice that is understood to be a common experience, as a potential source of catharsis and solidarity for participants, 
and an issue for participants to organise around and advocate change. They were also concerned about the difficulties they had experienced as part of previous work on the project regarding participant recruitment (e.g. people who agreed to participate, and then did not show up). This reluctance to participate also occurred within workshops, where most participants tended to hold back until someone else shared their experiences.

Pilot 3 focused more on practical aspects of when and where the workshops would be held, rather than the content of the workshops (which included an interest in combining activities into a single longer workshop). This can likely be attributed to their background and familiarity with qualitative research and academic work. The discussion had a different pragmatic focus, as Pilot 3 was also interested in creating and publishing a digital book to give back to participants, based on the research and good practices that formed their contribution to the report [3], which could be used to help recruit participants for the design workshop.

Moreover, the participatory activities conducted by pilot partners unveiled a significant issue concerning communication, which mainly related to the rejection or skepticism that participants in the different countries expressed towards the bureaucratic language, typical of funding institutions, whereby the grant proposal and the official communication of the project was originally crafted. As a consequence, the consortium decided to change all its communication materials (flyers, posters, logo, stickers, etc.), starting from the very name of the project: from PIE News to Commonfare [14].

\section{DISCUSSION AND CONCLUSION}

Where some actions were more obviously strategic - such as the planning and development of the field activities plan - others, such as the tailoring meetings, the resulting workshops and focus groups conducted by the pilot partners, and the change of communication present a tactical character. In de Certeau [5] terms, where we have established strategic plans to achieve specific research goals (e.g. feedback on the existing release and insight for future releases of Commonfare.net), the tactical actions can be considered as taking place in "the space of the other", where pilot partners have control and autonomy to calculate, plan and situate their actions as they engage with participants.

From our perspective, the pilot partners are the gateway to the participants as they interpret our goals and suggested approaches, add their own expertise and perspective. This appears as a series of tactical actions taken, acting within the space of specific research goals. From the perspective of the pilot partners, however, they develop plans and take action within their country, with groups of participants with whom relationships are cultivated, and this is their strategic concern. Here we see a tension of the kind of relationship we have described: first, as an ICT and research project, funded by the EU, the project proposal set constraints in terms of deadlines, effort, language, etc., with the goal of designing and delivering an ICT artifact, the Commonfare.net platform. Second, the project has always been framed as privileging the relationships the pilot partners could establish in their respective social context and that should be driving the design, as a way to grant that the design and implementation provides something meaningful for the people involved. Therefore, the establishment of place can therefore be understood as a mixture of tactical and strategic actions, in which different actors find themselves without a constant positioning.

What is interesting about discussing our research project in terms of strategies and tactics is that there are no clear roles in terms of power, as each actor can move between tactical and strategic actions depending on the particularities of each situated case. In fact, regarding the Commonfare project, the original intent was tactical: to bring discourses on inequalities and welfare into the EU-funded ICT research and innovation programs, even using the their language and rhetoric around technology, innovation and societal challenges. Through networking and the construction of alliances with other organisations, a strategic plan was elaborated and inscribed into the project proposal that was eventually funded by the EU. Nevertheless, the positioning into the EU framework was not neutral and impacted the way through which the strategic plan - the project proposal - was elaborated, pushing toward the need for new tactical practices once the project started [14].

In sum, we have sought to provide an account of the Commonfare project, and an example of the interactions between pilot and research partners, to highlight the strategic and tactical actions as a reflective exercise to understand the power dimension of actors within the infrastructuring process. We argue that the concepts of strategies and tactics provide a useful lens to understand different perspectives and actions taken within participatory design projects in which the designers contribute their skills into a wider alliance. In particular, that strategies and tactics increase the visibility of where planning, or other partners' strategic concerns, become the space for tactical re-appropriation, and that this process is not only normal but also fruitful for collaborative and participatory forms of infrastructuring.

\section{ACKNOWLEDGMENTS}

This project has received funding from the European Union's Horizon 2020 research and innovation programme under grant agreement No. 687922. The presentation of this paper has been supported by the COST Association, specifically the CA16121 action SharingAndCaring. 


\section{REFERENCES}

[1] Emiliana Armano, Annalisa Murgia, and Maurizio Teli. 2017. Platform capitalism e confini del lavoro negli spazi digitali. Mimesis.

[2] Jeffrey Bardzell and Shaowen Bardzell. 2015. The User Reconfigured: On Subjectivities of Information. In Proceedings of The Fifth Decennial Aarhus Conference on Critical Alternatives (AA '15). Aarhus University Press, 133-144. https://doi.org/10.7146/aahcc.v1i1.21298

[3] BIN ITALIA. 2017. Research Report 2.1. University of Trento, Basic Income Network Italy, Centre for Peace Studies, Museu da Crise (Daniela Paes Leão and Merel Willemsen), CREATE-NET, Stichting Dyne.org, Abertay University, Madeira Interactive Technologies Institute (3 2017). http://pieproject.eu/wp-content/uploads/2017/03/PIE_D2.1.pdf

[4] Susanne Bødker, Henrik Korsgaard, Peter Lyle, and Joanna SaadSulonen. 2016. Happenstance, Strategies and Tactics: Intrinsic Design in a Volunteer-based Community. In Proceedings of the 9th Nordic Conference on Human-Computer Interaction (NordiCHI '16). ACM, New York, NY, USA, Article 10, 10 pages. https://doi.org/10.1145/2971485. 2971564

[5] Michel de Certeau. 1984. The Practice of Everyday Life. University of California Press.

[6] Lynn Dombrowski, Ellie Harmon, and Sarah Fox. 2016. Social JusticeOriented Interaction Design: Outlining Key Design Strategies and Commitments. In Proceedings of the 2016 ACM Conference on Designing Interactive Systems (DIS '16). ACM, New York, NY, USA, 656-671. https: //doi.org/10.1145/2901790.2901861

[7] Paul Dourish. 2006. Re-space-ing Place: "Place" and "Space" Ten Years on. In Proceedings of the 2006 20th Anniversary Conference on Computer Supported Cooperative Work (CSCW'06). ACM, New York, NY, USA, 299-308. https://doi.org/10.1145/1180875.1180921

[8] Hamid R. Ekbia and Bonnie A. Nardi. 2017. Heteromation, and Other Stories of Computing and Capitalism. MIT Press. Google-Books-ID: WXPGDgAAQBAJ.

[9] Eurostat. 2017. People at risk of poverty or social exclusion - Statistics Explained. (2017). http://ec.europa.eu/eurostat/statistics-explained/ index.php/People_at_risk_of_poverty_or_social_exclusion

[10] H. Karasti and K. S. Baker. 2004. Infrastructuring for the long-term: ecological information management. In Proceedings of the 37th Annual Hawaii International Conference on System Sciences, 2004.10 pp.-. https: //doi.org/10.1109/HICSS.2004.1265077

[11] Volkmar Pipek and Volker Wulf. 2009. Infrastructuring: Toward an integrated perspective on the design and use of information technology. Journal of the Association for Information Systems 10, 5 (2009), 447.

[12] David Roedl, Shaowen Bardzell, and Jeffrey Bardzell. 2015. Sustainable Making? Balancing Optimism and Criticism in HCI Discourse. ACM Trans. Comput.-Hum. Interact. 22, 3, Article 15 (June 2015), 27 pages. https://doi.org/10.1145/2699742

[13] Trebor Scholz. 2016. Uberworked and Underpaid: How Workers Are Disrupting the Digital Economy. John Wiley \& Sons. Google-Books-ID: LiDNDQAAQBAJ.

[14] Mariacristina Sciannamblo and Maurizio Teli. 2017. Undoing the Ontology of the Poor: A Participatory Design Project. (2017). http://www.4sonline.org/blog/post/undoing_the_ontology_of_ the_poor_a_participatory_design_project

[15] Susan Leigh Star and Geoffrey Bowker. 2002. How to Infrastructure. In Handbook of New Media: Social Shaping and Social Consequences of ICTs, L. A. Lievrouw and S. Livingstone (Eds.). Sage Publications, 151-162.

[16] Maurizio Teli, Angela Di Fiore, and Vincenzo D’Andrea. 2016. Computing and the Common: An Empirical Case of Participatory Design Today. In Proceedings of the 14th Participatory Design Conference: Full Papers - Volume 1 (PDC '16). ACM, New York, NY, USA, 1-10. https://doi.org/10.1145/2940299.2940312

[17] Maurizio Teli, Angela Di Fiore, and Vincenzo D’Andrea. 2017. Computing and the common: a case of Participatory Design with think tanks. CoDesign 13, 2 (2017), 83-95. https://doi.org/10.1080/15710882. 2017.1309439 arXiv:http://dx.doi.org/10.1080/15710882.2017.1309439 